\title{
Report of two unlinked cases of infant botulism in the UK in October 2007
}

\begin{abstract}
Correspondence
Kathie A. Grant

kathie.grant@hpa.org.uk
\end{abstract}

Received 8 June 2009

Accepted 5 August 2009

\author{
Kathie A. Grant, ${ }^{1}$ ljeoma Nwarfor, ${ }^{1}$ Obioma Mpamugo, ${ }^{1}$ Vina Mithani, ${ }^{1}$ \\ Paula Lister, ${ }^{2}$ Garth Dixon, ${ }^{3}$ Grainne Nixon, ${ }^{4}$ Timothy Planche, ${ }^{5}$ \\ Max Courtney, Jaime Morgan ${ }^{6}$ and Jim McLauchlin ${ }^{7}$ \\ ${ }^{1}$ Foodborne Pathogen Reference Unit, Health Protection Agency (HPA), Centre for Infections, \\ London NW9 5EQ, UK \\ ${ }^{2}$ Paediatric Intensive Care Unit, Great Ormond Street Hospital, Great Ormond Street, London, UK \\ ${ }^{3}$ Department of Microbiology, Great Ormond Street Hospital, Great Ormond Street, London, UK \\ ${ }^{4}$ North East \& Central London Health Protection Unit, London, UK \\ ${ }^{5}$ Department of Medical Microbiology, St George's Hospital, London, UK \\ ${ }^{6}$ Surrey and Sussex Health Protection Unit, Leatherhead, Surrey, UK \\ ${ }^{7}$ Health Protection Agency Regional Microbiology Network, London, UK
}

\begin{abstract}
Infant botulism is a rare disease in the UK, with the first case being recognized in 1978 and only five subsequent cases being reported before 2007. This study reports two unlinked cases of infant botulism, caused by two distinct strains of Clostridium botulinum (toxin types $A$ and $B$, respectively), that occurred within a single month in the south-east of England in October 2007. The use of real-time PCR to detect $C$. botulinum neurotoxin genes in clinical specimens to improve the diagnostic procedure and to follow carriage of the causative organism in the infant gut is described. The laboratory investigation of these two cases demonstrated that a combination of the mouse bioassay, real-time PCR assays and conventional microbiological culture can provide rapid confirmation of a clinical diagnosis and affect patient management. Both infants (aged 4 and 8 months) were previously healthy prior to the onset of symptoms, and in both cases, a diagnosis of infant botulism was delayed for at least 10 days after initial admission to hospital. Once diagnosed, one of the infants was the first in the UK to be treated with human-derived botulism immunoglobulin. Real-time PCR was used to demonstrate that $C$. botulinum was excreted in the infants' faeces for up to 68 and 81 days, respectively. Despite the infrequency of infant botulism in the UK, clinicians should be aware of this rare but serious condition and should seek microbiological advice when presented with young infants with compatible symptomologies.
\end{abstract}

\section{INTRODUCTION}

Infant botulism is a disease that involves a descending bilateral paralysis, usually within the first 6 months after birth, and presents with characteristic symptoms including constipation, difficulty feeding, lethargy, decreased head control, ptosis and difficulties with breathing: hence the name floppy baby syndrome (Arnon, 1992). The characteristic flaccid paralysis may persist for several weeks to months and ventilation may be required in the more severely affected cases. The disease results from colonization of the intestine by Clostridium botulinum and

Abbreviations: AFLP, amplified fragment length polymorphism; FPRU, Foodborne Pathogen Reference Unit; IBTPP, Infant Botulism Treatment and Prevention Program. production of neurotoxin in vivo. Toxin is absorbed across the intestinal mucosa and transported via the circulation to neuromuscular junctions and other peripheral cholinergic synapses where it binds irreversibly, resulting in blocking the release of the neurotransmitter acetylcholine. Laboratory confirmation of the clinical diagnosis requires detection of botulinum toxin in serum or faeces using a neutralization bioassay and/or the recovery of C. botulinum from faeces (Arnon, 1992; CDC, 1997).

The source of C. botulinum is not known for the majority of cases of infant botulism; however, honey and corn syrup have been identified as sources of the organism in a small number of cases (Arnon et al., 1979; Arnon, 1992; Crawford \& Gorrell, 2002). The bacterium is widely distributed in soil, dust and the environment, as well as 
in other foods, and all have been postulated as reservoirs (Arnon et al., 1979; Arnon, 1992; Crawford \& Gorrell, 2002).

Until recently, the only treatment for infant botulism was supportive therapy, as the antitoxin used to treat botulism in adults affords too great a risk of adverse reaction in infants. However, in 2003, human-derived botulism immunoglobulin became available (BabyBIG) and was licensed in the USA for the treatment of infant botulism (Arnon et al., 2006). The use of BabyBIG in the USA has been shown to reduce the length of hospital stay and associated hospital costs significantly (Arnon et al., 2006). In order to be effective, this treatment needs to be given as early in the onset of disease as possible so that circulating neurotoxin is prevented from reaching its target.

In the UK, there have been six reported cases of infant botulism between 1978 and 2006 (Turner et al., 1978; Smith et al., 1989; Jones et al., 1990; CDSC, 1993, 1994; Brett et al., 2005). We report here the results of microbiological and molecular studies on two apparently unrelated cases that occurred in October 2007. We also describe the use of real-time PCR to substantially improve the diagnostic process for infant botulism and thus facilitate rapid and appropriate patient management, as well as providing information to assess risks from foods and the environment.

\section{METHODS}

Microbiological methods. Serum and faecal extracts from two cases were tested for the presence of botulinum neurotoxins using a neutralization mouse bioassay (CDC, 1998). A portion of faecal extract from one case was trypsinized before testing by mouse bioassay. Monovalent neutralizing antisera were supplied by the Centers for Disease Control and Prevention, GA, USA, and appropriate UK Home Office licences were held for performance of the bioassay.

Faecal, food and medicinal products were examined for C. botulinum by enrichment in pre-reduced cooked meat medium (CMM) broth with added glucose and starch (CDC, 1998). Soil and vacuum cleaner dust were cultured as described by Nevas et al. (2005) by inoculation into pre-reduced CMM broth with added glucose and starch. Duplicate specimens and samples were inoculated into pre-reduced $\mathrm{CMM}$, one of which was heat-shocked at $60{ }^{\circ} \mathrm{C} \pm 2{ }^{\circ} \mathrm{C}$ for $30 \mathrm{~min}$. Enrichment cultures were incubated anaerobically at $30{ }^{\circ} \mathrm{C}$ for up to 5 days and subcultured onto solid medium with or without antibiotics after 1, 3 and 5 days' incubation (Dezfulian et al., 1981). Plates were incubated in an anaerobic cabinet (Don Whitley Scientific) at $30{ }^{\circ} \mathrm{C}$ in an atmosphere of $80 \% \mathrm{~N}_{2}, 10 \% \mathrm{H}_{2}$ and $10 \% \mathrm{CO}_{2}$ for $1-5$ days.

For DNA extraction from CMM broths, the biomass from $1 \mathrm{ml}$ was harvested by centrifugation at $13000 \mathrm{~g}$ for $3 \mathrm{~min}$, washed once in $1 \mathrm{ml}$ nuclease-free water (Sigma) and resuspended in $200 \mu \mathrm{l}$ premixed Instagene matrix (Bio-Rad Laboratories) by vortexing. Samples were then heated for $30 \mathrm{~min}$ at $56{ }^{\circ} \mathrm{C}$, followed by $8 \mathrm{~min}$ at $100{ }^{\circ} \mathrm{C}$, and DNA present in the supernatant was recovered by centrifugation. DNA was extracted from inoculated broths after 1, 3 and 5 days' incubation and tested for the presence of $C$. botulinum neurotoxin (bont) genes by real-time PCR. DNA was extracted from individual bacterial colonies using microLYSIS (Microzone), a rapid DNA release reagent, following the manufacturer's instructions. Briefly, a portion of a single colony was mixed into $19 \mu \mathrm{l}$ microLYSIS reagent using a sterile disposable $1 \mu \mathrm{l}$ microbiological loop and heated in a thermocycler using the following cycle: $65{ }^{\circ} \mathrm{C}$ for $5 \mathrm{~min}, 96{ }^{\circ} \mathrm{C}$ for $2 \mathrm{~min}, 65{ }^{\circ} \mathrm{C}$ for $4 \mathrm{~min}, 96{ }^{\circ} \mathrm{C}$ for $1 \mathrm{~min}, 65{ }^{\circ} \mathrm{C}$ for $1 \mathrm{~min}$ and $96{ }^{\circ} \mathrm{C}$ for $30 \mathrm{~s}$, followed by $20^{\circ} \mathrm{C}$ hold. DNA extracts were then tested for the presence of bont genes by real-time PCR assays.

Real-time PCR assays. Real-time PCR assays for bont $A$, bontB and bontE gene fragments were performed as described previously (Akbulut et al., 2004) except that PCR primers (F1: 5'-CCTGCAATTTCACTAGCTCATGA-3'; F2: 5'-GCCTTATGGGTTTTTCGGCTAT-3') and a 5' Yakima Yellow-labelled fluorescent probe (5'-TTGATACATGCACTGCATGGATTATACGGG-3') were also included for the specific detection of a fragment of the bont $F$ gene. PCR analysis was performed as two duplex reactions: one for the detection of bontA and bontB gene fragments, and the other for the detection of bontE and bont $F$ gene fragments. To detect any inhibition of PCR from extracted DNA, a commercially available internal control assay (Applied Biosystems) was run independently on all DNA samples. All assays were performed in duplicate in 96-well MicroAmp optical plates with MicroAmp optical plate seals (Applied Biosystems). Each reaction comprised $25 \mu$ l containing $1 \times \mathrm{qPCR}$ Master Mix (Eurogentec), $0.1 \mu \mathrm{M}$ of the appropriate fluorescent probe, $0.3 \mu \mathrm{M}$ each of the corresponding reverse and forward oligonucleotide primers and $5 \mu \mathrm{l}$ DNA extract. Negative controls of sterile distilled water only and positive controls containing $5 \mu \mathrm{l}$ extracted DNA from NCTC strains of C. botulinum types A, B, E and $\mathrm{F}$ were included in each assay.

Amplification and detection were performed under the default conditions of an ABI Prism 7000 Sequence Detection System, which comprised: $2 \mathrm{~min}$ at $55^{\circ} \mathrm{C}$ and $10 \mathrm{~min}$ at $95{ }^{\circ} \mathrm{C}$, followed by 40 cycles of $95{ }^{\circ} \mathrm{C}$ for $15 \mathrm{~s}$ and $60{ }^{\circ} \mathrm{C}$ for $1 \mathrm{~min}$. PCR products were detected by monitoring the increase in fluorescence due to release of reporter dyes from the probes, resulting from the heat-dependent $5^{\prime}$ exonuclease activity of Taq polymerase. Assay results were calculated using the manufacturer's software as signal threshold cycle $\left(C_{\mathrm{T}}\right)$ values, where $C_{\mathrm{T}}$ is the PCR cycle number at which fluorescence of the released reporter dye reaches a threshold level. Samples were designated positive when $C_{\mathrm{T}}$ values of $<35$ were obtained and negative for $C_{\mathrm{T}}$ values of $\geqslant 35$.

\section{Amplified fragment length polymorphism (AFLP) analysis. AFLP for molecular fingerprinting of isolates was performed in a manner similar to that described previously (Brett et al., 2005). DNA was extracted from pure cultures of C. botulinum growing on Columbia blood agar plates after $48 \mathrm{~h}$ at $30^{\circ} \mathrm{C}$ in an anaerobic cabinet using a previously described automated method (Akbulut et al., 2004). Restriction digestion of DNA and ligation of the adaptors were performed in a single step using a modification of the method of Valsangiacomo et al. (1995). Briefly, $5 \mu \mathrm{l}(\sim 4 \mu \mathrm{g})$ extracted DNA was digested with $20 \mathrm{U}$ HindIII (Sigma) and ligated to adaptor oligonucleotides $\mathrm{ADH} 1$ and $\mathrm{ADH} 2(1 \mu \mathrm{M}$ each; MWG-Biotech) using $1 \mathrm{U}$ T4 ligase (Invitrogen) and T4 DNA ligase buffer [250 mM Tris/ $\mathrm{HCl}$ (pH 7.6), $50 \mathrm{mM} \mathrm{MgCl}_{2}, 5 \mathrm{mM}$ ATP, $5 \mathrm{mM}$ dithiothreitol, $25 \%(\mathrm{w} / \mathrm{v})$ polyethylene glycol 8000 ] in a final volume of $35 \mu \mathrm{l}$. Digestion of DNA and ligation of adaptors to restriction fragments was performed at $37{ }^{\circ} \mathrm{C}$ for $90 \mathrm{~min}$ in a thermal cycler. The ligated DNA was heated to $80{ }^{\circ} \mathrm{C}$ for $10 \mathrm{~min}$ and diluted $1: 5$ in sterile distilled water, and $5 \mu$ l was used for each PCR.}

PCRs were performed in $25 \mu \mathrm{l}$ final volumes and contained $5 \mu \mathrm{l}$ diluted ligated DNA, $2.5 \mathrm{mM} \mathrm{MgCl} 2,300 \mathrm{ng}$ primer $\mathrm{HI}-\mathrm{C}\left(5^{\prime}\right.$ GGTATGCGACAGAGCTTC-3'; Gibco-BRL), which binds to the ligated adaptor sequences, and 1.25 U Taq DNA polymerase in $1 \times$ PCR buffer (Gibco-BRL). The mixture was subjected to an initial 
denaturing step of $94{ }^{\circ} \mathrm{C}$ for $4 \mathrm{~min}$, followed by 35 cycles of $1 \mathrm{~min}$ at $94{ }^{\circ} \mathrm{C}, 1 \mathrm{~min}$ at $60{ }^{\circ} \mathrm{C}$ and $2.5 \mathrm{~min}$ at $72{ }^{\circ} \mathrm{C}$. A non-template control was included in each batch of tests. Banding patterns were resolved by running $13 \mu \mathrm{l}$ of the amplified product in a $1.5 \%$ agarose gel containing $0.5 \mu \mathrm{g}$ ethidium bromide $\mathrm{ml}^{-1}$ and were observed under UV transillumination. Fluorescent bands were recorded with a Gel Doc 2000 gel documentation system (Bio-Rad Laboratories), and banding patterns from different C. botulinum isolates were compared by visual inspection.

\section{RESULTS AND DISCUSSION}

On 10 October 2007, the HPA Foodborne Pathogen Reference Unit (FPRU) was contacted about a possible case of infant botulism. A previously healthy, predominantly breastfed, 8 -month-old male infant was admitted to a hospital in London on 29 September with a 2-day history of poor feeding and lethargy. The infant became increasingly floppy and had poor urine output. Upon examination, the infant was apyrexial and had a clear chest and normal perfusion, but had globally reduced power and tone. A chest radiograph revealed a large cardiothoracic ratio, and blood gas analysis showed metabolic acidosis. Presumptive sepsis was treated empirically with broadspectrum antibiotics and acyclovir. The baby was transferred to a second London hospital on 30 September for further assessment and on 1 October developed respiratory failure secondary to progressive weakness, requiring intubation and ventilation. A differential diagnosis of Guillain-Barré syndrome was initially suspected, but electromyography tests and cerebrospinal fluid results being inconclusive, infant botulism was considered. On 11 October, serum and faeces inoculated into CMM broth were sent to the FPRU for testing. The following day, $C$. botulinum neurotoxin was detected in serum and faeces from the infant by mouse bioassay and bontA genes were detected by real-time PCR in enrichment cultures from infant faeces. It is of note that C. botulinum type A was detected and isolated only from a non-heat-shocked enrichment broth inoculated with the original CMM broth containing faeces provided by the hospital microbiology laboratory. C. botulinum was not isolated from a duplicate enrichment broth that had been heat-shocked, nor from any enrichment broths inoculated directly with faeces by the reference laboratory. This indicated that viable $C$. botulinum cells were present in the faeces from the infant and that these were recoverable when faeces was inoculated into CMM by the sending laboratory; however, by the time the reference laboratory inoculated faeces into CMM, the bacteria were no longer viable and C. botulinum was not detected by PCR or isolated from enrichment culture. $C$. botulinum is a strict anaerobe and in order to maximize the likelihood of detection and isolation of C. botulinum from clinical material, specimens should be inoculated into $\mathrm{CMM}$ as soon as possible after being taken and transported to the reference laboratory. C. botulinum type A was isolated subsequently in pure culture from the non-heatshocked enrichment broth and shown to have typical phenotypic characteristics on diagnostic agar (lipasepositive and lecithinase-negative) and to also contain the bont $A$ gene. The isolate was confirmed as C. botulinum type A by the Anaerobic Reference Laboratory, Cardiff, UK. C. botulinum type A isolates from sequential infant faecal samples were characterized by AFLP analysis.

This infant was treated on 14 October with BabyBIG (human-derived botulism antitoxin immunoglobulin) obtained from the Infant Botulism Treatment and Prevention Program (IBTPP) in California, USA, and showed some improvement, but continued to receive supportive care in the paediatric intensive care unit. This was the first case of infant botulism to be treated with BabyBIG in the UK. After antitoxin therapy, the infant was also treated with metronidazole. The infant was transferred to a paediatric intensive care unit in another hospital in the UK in November 2007, where he remained for several months before being discharged.

On 20 October 2007, a second male infant of 4 months was admitted to a different hospital in the south-east of England with a 2-day history of feeding difficulties, ptosis and breathing difficulties and who had been suffering from constipation since 11 October. This infant had received antibiotic therapy (trimethoprim) for 7 weeks, including the whole of September, for a urinary tract infection. On 29 October, the infant was transferred to a hospital in a different part of London to that caring for the first case, for further assessment and where a differential diagnosis of myasthenia gravis or infant botulism was made. On the same day, a rectal washout and a CMM broth inoculated with rectal washout from the infant were submitted to the FPRU. The following day, bontB genes were detected by real-time PCR in the CMM inoculated with rectal washout by the sending laboratory, as well as in both heat-shocked and non-heat-shocked enrichment broths inoculated with rectal washout by the reference laboratory. In this instance, the rectal washout and CMM inoculated with rectal washout were received by the reference laboratory on the day they were taken, thus minimizing the length of time the rectal washout was subjected to non-anaerobic conditions. This is likely to explain why C. botulinum was detected and isolated from all enrichment cultures, unlike the first case described here. C. botulinum type B was isolated in pure culture from faeces and demonstrated typical phenotypic characteristics on diagnostic agar (lipase-positive and lecithinase-negative) and contained the bontB gene. It was confirmed as a type B, proteolytic $C$. botulinum by the Anaerobic Reference Laboratory, Cardiff. C. botulinum type $B$ isolates from sequential faecal samples were characterized by AFLP analysis. Type B botulinum neurotoxin was detected only following trypsinization of a rectal washout extract and thus, in this case, a diagnosis of infant botulism was confirmed on the basis of PCR detection of bontB genes from a rectal washout.

Treatment of the infant with BabyBIG was discussed with clinicians at the IBTPP, but as the infant did not show signs 
of severe intoxication and was showing signs of improvement, a decision not to treat was taken, unless there was a sudden deterioration in the progress of the infant.

The occurrence of two cases of infant botulism within a single month is unprecedented in the UK, although elsewhere in the world, in the USA for example, infant botulism is diagnosed far more frequently. It is suspected that the two UK cases were independent and an increase in diagnostic awareness is considered unlikely, as neither of the two groups of staff caring for these infants were aware of the other case prior to contacting the FPRU. Because this is such a rare disease in the $\mathrm{UK}$, it may not be readily considered, as demonstrated by these two cases where infants were ill and hospitalized for 13 and 10 days, respectively, before infant botulism was considered. For BabyBIG to be effective, it must be administered early in the onset of disease and it is therefore important that symptoms such as constipation, difficulty feeding, generalized weakness and bulbar palsies including ptosis and floppiness in infants less than 1 year of age raise a clinical suspicion of infant botulism.

All eight cases of confirmed infant botulism in the UK (Table 1) have shown features typical of those described in other countries (Arnon et al., 1979; Arnon, 1992; Crawford \& Gorrell, 2002). Three of the UK cases were due to type A, four to type $B$ and one was caused by an isolate producing both $\mathrm{B}$ and $\mathrm{F}$ toxins. Toxin was detected in the faeces in seven cases and in serum in four cases, and the organism was isolated from the faeces in seven cases (Table 1). Seven of the infants were under 6 months of age and the remaining infant (one of the cases described here) was 8 months old. Five of the infants were at the more severe end of the clinical spectrum and required ventilation. Possible risk factors were identified for a number of the cases: one had a history of travel to Spain, another developed symptoms while in the Yemen and then travelled to the UK, three had consumed honey, one had consumed infant formula milk and five were being weaned. Neither of the two infants in the botulism cases occurring in 2007 had consumed honey or had a history of travel outside the UK. The infant in the first case in 2007 had begun weaning, and it has been proposed that perturbation in the infant gut flora that occurs with weaning provides a window of opportunity for C. botulinum spores to germinate, multiply and produce neurotoxin (Arnon, 1995; Fox et al., 2005). The infant in the second case in 2007 had received antibiotic treatment for a urinary tract infection for several weeks prior to developing symptoms of infant botulism and this may have perturbed the gut flora, enabling C. botulinum spores to germinate and produce neurotoxin.

Advances in nucleic acid detection technologies have seen a huge increase in real-time PCR-based methods for the detection of a wide range of microbial pathogens. We reported previously on the evaluation of these assays for the diagnosis of botulism, which allows online monitoring of amplified gene fragments at each cycle of PCR, thus permitting simultaneous amplification and detection at high sensitivities of pathogen-specific nucleic acids within 1-2 h (Akbulut et al., 2004, 2005). Additionally here, we included the use of a fourth real-time PCR to detect a fragment of the bontF gene. The use of real-time PCR for bont genes has provided a potentially faster, less expensive and ethically more acceptable approach (fewer bioassays are necessary) to conventional laboratory diagnostic approaches.

Botulinum neurotoxins are synthesized as a single polypeptide which becomes active only following proteolytic cleavage to generate two subunits. It is of note that toxin was only detected by mouse bioassay in the faeces of the infant in the second case described here following in vitro treatment with trypsin. This observation may explain

Table 1. Summary of cases of infant botulism confirmed in the UK

\begin{tabular}{|c|c|c|c|c|c|c|c|}
\hline \multirow[t]{2}{*}{$\begin{array}{l}\text { Month and } \\
\text { year of onset }\end{array}$} & \multirow[t]{2}{*}{ Age/sex } & \multirow[t]{2}{*}{$\begin{array}{c}\text { Received } \\
\text { ventilation }\end{array}$} & \multirow[t]{2}{*}{ Risk factors } & \multirow[t]{2}{*}{$\begin{array}{l}\text { Toxin } \\
\text { type }\end{array}$} & \multicolumn{2}{|c|}{$\begin{array}{l}\text { Confirmation of botulism by } \\
\text { isolation of } C \text {. botulinum or } \\
\text { detection of toxin in: }\end{array}$} & \multirow[t]{2}{*}{ Reference } \\
\hline & & & & & Faeces & Serum & \\
\hline December 1978 & 5 months/female & No & Weaning & A & Organism and toxin & & Turner et al. (1978) \\
\hline June 1987 & 4 months/male & Yes & Weaning & $\mathrm{B}(\mathrm{F})$ & Organism and toxin & & Smith et al. (1989) \\
\hline $\begin{array}{l}\text { Month unknown } \\
1989\end{array}$ & 2 months/female & No & $\begin{array}{l}\text { Symptoms developed } \\
\text { in the Yemen and fed } \\
\text { honey }\end{array}$ & $\mathrm{B}$ & Toxin & & Jones et al. (1990) \\
\hline June 1993 & 4 months/female & Yes & Travel to Spain & B & Organism and toxin & Toxin & CDSC (1993) \\
\hline January 1994 & 4 months/male & Yes & $\begin{array}{l}\text { Weaning and fed } \\
\text { honey }\end{array}$ & A & Organism and toxin & Toxin & CDSC (1994) \\
\hline June 2001 & 5 months/female & Yes & Weaning & B & Organism and toxin & & Brett et al. (2005) \\
\hline September 2007 & 8 months/male & Yes & Weaning & A & Organism & Toxin & This report \\
\hline October 2007 & 4 months/male & No & Antibiotic treatment & B & Organism and toxin & Toxin & This report \\
\hline
\end{tabular}


Table 2. Comparison of two cases of infant botulism in England in 2007

\begin{tabular}{|c|c|c|}
\hline Feature & Case 1 & Case 2 \\
\hline Age/sex & 8 months/male & 4 months/male \\
\hline Toxin type & A & $\mathrm{B}$ \\
\hline Ventilated & Yes & No \\
\hline Nasogastric feeding & Yes & Yes \\
\hline \multicolumn{3}{|l|}{ Samples of faeces tested for $C$. botulinum: } \\
\hline Detected & 23,27 and 28 days after onset & $18,24,32,39$ and 46 days after onset \\
\hline Not detected & $37,57,61$ and 68 days after onset & 53,76 and 81 days after onset \\
\hline $\begin{array}{l}\text { Food and environmental samples collected } \\
\text { from home, C. botulinum not isolated }\end{array}$ & $\begin{array}{l}\text { Honey, maple syrup, sesame seeds, millet } \\
\text { seeds, rice and millet porridge, rice cakes, } \\
\text { soil }\end{array}$ & $\begin{array}{l}\text { Honey, gripe water, infant paracetamol sus- } \\
\text { pension, infant wind-relief suspension, soil }\end{array}$ \\
\hline $\begin{array}{l}\text { C. botulinum neurotoxin genes detected in } \\
\text { vacuum cleaner dust by PCR }\end{array}$ & $\begin{array}{l}\text { Type A detected; types B, E and F not } \\
\text { detected }\end{array}$ & Type B detected; types A, E and F not detected \\
\hline
\end{tabular}

the less severe symptoms in this case compared with the first case.

Weekly samples of faeces were collected from the case 1 infant between 23 and 68 days after onset, and from the case 2 infant between 18 and 81 days after onset (Table 2). C. botulinum type A was isolated from the case 1 infant on days 23-28 (three samples) but not after 37 days. C. botulinum type B was isolated from the faeces of the case 2 infant on days 18-46 (four samples) but not after 53 days. It was not possible with any of the earlier UK cases to estimate the length of carriage of $C$. botulinum due to restrictions on the use of laboratory animals. However, the use of a PCR assay for detection of bont genes has, for the first time in the UK, enabled carriage of the organism in the human infant gut to be monitored. The observations on the two cases described here illustrate the potential for prolonged excretion of the bacterium and its neurotoxins in the faeces of affected infants, which is a source of exposure to contacts both within and outside hospital settings, including other infants. The IBTPP (California Department of Public Health; Anonymous, 2008) recommends scrupulous attention to hand washing by all hospital personnel who have contact with the infant, and that persons with open lesions on their hands should not handle soiled nappies. Close contact between these babies and other infants (including sharing cots and toys) should be avoided while excretion may be continuing. On the basis of this advice (Anonymous, 2008), both cases were barrier nursed and nappies were bagged and autoclaved prior to disposal until the organism was no longer detected on three subsequent occasions. In addition, cots from both homes were also disposed. No adverse infection control incidents were detected. The length of time of carriage for case 1 was much less than for the second case and this is most likely to be linked to the case 1 infant being treated with metronidazole following administration of BabyBIG. Antibiotic treatment to eliminate C. botulinum is not recommended in cases of infant botulism, as it can lead to the release of neurotoxin from bacterial cells. However, the case 1 infant had been treated with antitoxin prior to administration of metronidazole.

Molecular fingerprinting of the C. botulinum isolates using AFLP showed that each infant was colonized by a distinct strain, and this remained present in the faeces throughout the period of carriage (Fig. 1). These results are in contrast to those from a previous case in England in 2001 where multiple strains of $C$. botulinum were detected at the time of diagnosis (Brett et al., 2005).

The infant in the first case in 2007 had been breastfed on demand, and there was no history of formula feed, dairy products, gluten, meat, fish, sugar, honey, syrup, eggs, or canned or jars of food. This infant had eaten some organic fruit and vegetables, which were cooked thoroughly and pureed, and either eaten straight away or eaten within

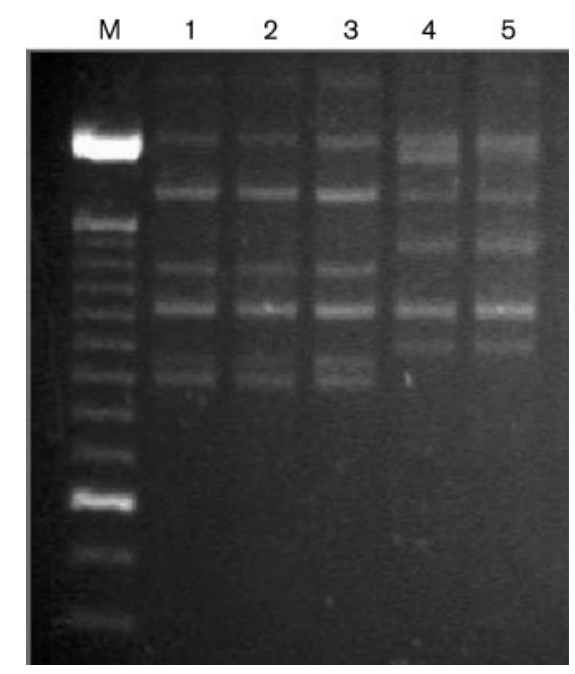

Fig. 1. AFLP profiles of C. botulinum isolates from two infant botulism cases in 2007. Lanes: M, 100 bp DNA size marker; 1-3, isolates from first case after 23,27 and 28 days, respectively; 4 and 5 , isolates from case 2 after 18 and 46 days, respectively. 
1 day after refrigeration. This infant had also eaten unsalted rice cakes, as well as porridge and millet. The second infant had been breastfed only, except for one feed of ready-prepared infant formula milk on 30 September. Foods, medicinal products (including infant paracetamol syrup and wind-relief suspension) and soil samples were collected from the homes of both infants (Table 2) and $C$. botulinum was not detected in any of these. However, the same botulinum neurotoxin gene as occurred in the infants' faeces was detected by PCR in samples of vacuum cleaner dust from both households. Due to contamination with other bacterial species, it was not possible to isolate $C$. botulinum in pure culture from either of these samples. These findings, however, do not provide evidence of dust as a source of infection, as the organisms detected in the vacuum cleaner may have originated from the infants themselves, following infection. As mentioned earlier, dust, as well as soil, the environment and foods, have all been postulated as reservoirs for C. botulinum (Arnon et al., 1979; Arnon, 1992; Crawford \& Gorrell, 2002). It is not clear why two 'unrelated' cases should occur within a short time period and we are not aware of any reason for an increase in environmental contamination in the south-east of England by C. botulinum types A and B. It may be of note that, where information was available for infant botulism in the UK (Table 1), cases predominantly occurred during the summer and autumn, in common with the two recent cases, when dust might be more likely to occur. Smart et al. (1987) reported that C. botulinum type $\mathrm{C}$ became more common in cattle in the UK during the 1980s following changes in poultry farming practices. It is not known whether other similar changes in agricultural practices might alter the ecology of these bacteria and increase exposure from the environment. At the time of writing (July 2009), no further cases have been detected in the UK, but if more cases are detected, there would be justification in re-examining the ecology of this bacterium.

\section{ACKNOWLEDGEMENTS}

We would like to thank Dr Jon Brazier and colleagues at the HPA Anaerobic Reference Laboratory, Cardiff, UK, for confirming the identity of the C. botulinum isolates from the two cases of infant botulism.

\section{REFERENCES}

Akbulut, D., Grant, K. A. \& McLauchlin, J. (2004). Application and development of real-time PCR assays to detect fragments of the Clostridium botulinum types A, B and E neurotoxin genes for investigation of human foodborne and infant botulism. Foodborne Pathog Dis 1, 247-257.

Akbulut, D., Grant, K. A. \& McLauchlin, J. (2005). Improvement in laboratory diagnosis of wound botulism and tetanus amongst illegal injecting drug users by use of real-time PCR assays for neurotoxin gene fragments. J Clin Microbiol 43, 4342-4348.

Anonymous (2008). Infant Botulism Treatment Program. Division of Communicable Disease Control, California Department of Public Health. Available from: http://www.infantbotulism.org/. Accessed April 2008.

Arnon, S. S. (1992). Infant botulism. In Textbook of Pediatric Infectious Diseases, pp. 1095-1102. Edited by R. D. Feigin \& J. D. Cherry. Philadelphia: W. B. Saunders.

Arnon, S. S. (1995). Botulism as an intestinal toxaemia. In Infections of the Gastrointestinal Tract, pp. 257-271. Edited by M. J. Blaser, P. D. Smith, J. I. Ravdin, H. B. Greenberg \& R. L. Guerrant. New York: Raven Press.

Arnon, S. S., Midura, T. F., Damus, K., Thompson, B., Wood, R. M. \& Chin, J. (1979). Honey and other environmental risk factors for infant botulism. J Pediatr 94, 331-336.

Arnon, S. S., Schechter, R., Maslanka, S. E., Jewell, N. P. \& Hatheway, C. L. (2006). Human botulism immune globulin for the treatment of infant botulism. N Engl J Med 354, 462-471.

Brett, M. M., McLauchlin, J., Harris, A., O'Brien, S., Black, N., Roberts, D. \& Bolton, F. J. (2005). A case of infant botulism with a possible link to infant formula milk powder: evidence for the presence of more than one strain of Clostridium botulinum in clinical specimens and food. J Med Microbiol 54, 769-776.

CDC (1997). Case definitions for infectious conditions under public health surveillance. Morb Mortal Wkly Rep 46 RR10, 1-55.

CDC (1998). Botulism in the United States, 1899-1996. Handbook for Epidemiologists, Clinicians and Laboratory Workers. Atlanta: Centers for Disease Control and Prevention.

CDSC (1993). A case of infant botulism. Commun Dis Rep CDR Wkly $3,129$.

CDSC (1994). A case of infant botulism. Commun Dis Rep CDR Wkly 4, 53 .

Crawford, D. \& Gorrell, J. G. (2002). Infant botulism and corn syrup: a case report. J Pediatr Pharmacol Ther 7, 64-67.

Dezfulian, M., McCroskey, L. M., Hatheway, C. L. \& Dowell, V. R. (1981). Selective medium for isolation of Clostridium botulinum from human feces. J Clin Microbiol 13, 526-531.

Fox, C. K., Keet, C. A. \& Strober, J. B. (2005). Recent advances in infant botulism. Pediatr Neurol 32, 149-154.

Jones, S., Huma, Z., Haugh, C., Young, Y., Starer, F. \& Sinclair, L. (1990). Central nervous system involvement in infantile botulism. Lancet 335, 228.

Nevas, M., Lindstrom, M., Virtanen, A., Hielm, S., Kuusi, M., Arnon, S. S., Vuori, E. \& Korkeala, H. (2005). Infant botulism acquired from household dust presenting as sudden infant death syndrome. J Clin Microbiol 43, 511-513.

Smart, J. L., Jones, T. O., Clegg, F. G. \& McMurty, M. J. (1987). Poultry waste associated type C botulism in cattle. Epidemiol Infect 98, 73-79.

Smith, G. E., Hinde, F., Westmoreland, D., Berry, P. R. \& Gilbert, R. J. (1989). Infantile botulism. Arch Dis Child 64, 871-872.

Turner, H. D., Brett, E. M., Gilbert, R. J., Ghosh, A. C. \& Liebeschuetz, H. J. (1978). Infant botulism in England. Lancet 1, 1277-1278.

Valsangiacomo, C., Baggi, F., Gaia, V., Balmelli, T., Peduzzi, R. \& Piffaretti, J. C. (1995). Use of amplified fragment length polymorphism in molecular typing of Legionella pneumophila and application to epidemiological studies. J Clin Microbiol 33, 1716-1719. 